\title{
Hematoprotective effect of seleno-L-methionine on cyclophosphamide toxicity in rats
}

\section{Adnan Ayhanci, Suzan Yaman, Sila Appak \& Sibel Gunes}

To cite this article: Adnan Ayhanci, Suzan Yaman, Sila Appak \& Sibel Gunes (2009)

Hematoprotective effect of seleno-L-methionine on cyclophosphamide toxicity in rats, Drug and Chemical Toxicology, 32:4, 424-428, DOI: 10.1080/01480540903130682

To link to this article: http://dx.doi.org/10.1080/01480540903130682

\section{冓 Published online: 01 Oct 2009.}

Submit your article to this journal $\pi$

LII Article views: 27

Q View related articles $₫$ 


\title{
Hematoprotective effect of seleno-L-methionine on cyclophosphamide toxicity in rats
}

\author{
Adnan Ayhanci ${ }^{1}$, Suzan Yaman ${ }^{1}$, Sila Appak ${ }^{2}$ and Sibel Gunes ${ }^{1}$ \\ ${ }^{1}$ Department of Biology, Faculty of Arts and Science, Eskisehir Osmangazi University, Eskisehir, Turkey and \\ ${ }^{2}$ Department of Molecular Biology and Genetics, Izmir Institute of Technology, Izmir, Turkey
}

\begin{abstract}
Cyclophosphamide (CP) is a widely used antineoplastic drug that causes toxicity in the normal cell due to its metabolites. The major drawback of this drug is an undesirable myelosuppression. Selenium (Se) is a potent nutritional antioxidant that carries out biological effects by its incorporation into selenoproteins, such as glutathione peroxidase (GPX). The possible protective effects of seleno-L-methionine (SLM) against $\mathrm{CP}$-related toxicity of blood cells and bone marrow of rats were investigated in this study. Intraperitoneal (i.p) administration of 50,100 , or $150 \mathrm{mg} / \mathrm{kg}$ of CP caused, in a dose-dependent manner, reductions in the number of leukocytes $(78,89$, and $92 \%$, respectively), thrombocytes $(22,33$, and $52 \%$, respectively), and bone marrow-nucleated cells $(72,90$, and $94 \%$, respectively). The groups that had CP treatment alone were killed 3 days after the CP injection. For the groups having CP+SLM, SLM $(0.4$ or $0.8 \mathrm{mg} / \mathrm{kg}$ i.p) administration was started 3 days earlier than the $C P$ administration and continued to the end of the experiment ( 6 days). On day 4 , the animals were weighed again, relative doses of CP were estimated, and CP+SLM was administered together. On day 7, blood samples were collected and bone marrow of animals were resected under anesthesia. The results indicated that treatment of rats within a select dose range of SLM could reduce $\mathrm{CP}$-induced toxicity on blood cells and bone marrow.
\end{abstract}

Keywords: Cyclophosphamide; seleno-L-methionine; hematoxicity; cytoprotectivity; rats

\section{Introduction}

Cyclophosphamide (CP), a cytotoxic alkylating agent, is extensively used as an antineoplastic agent for the treatment of various cancers and as an immunosuppressive agent for organ transplantation, systemic lupus erythematosus, as well as for some other benign diseases (Selvakumar et al., 2006). $\mathrm{CP}$ is a prodrug that requires in vivo metabolism to form the reactive component, acrolein, and phosphoramide mustard (Anderson et al., 1995). These toxic metabolites have been shown to reduce lung microsomal enzyme activity and decrease the proper function of the antioxidant defense system in mammals (Kumari and Shaoo, 2005). Long-term CP treatment causes adverse effects, such as marked myelosuppression (Shah et al., 2008), which is a major potential toxic and dose-limiting side effect of CP. CP causes cross-linking of DNA and inhibits DNA synthesis by acting on both cyclic and intermitotic cells, resulting in a general depletion of immune component cells (George et al., 2008). In addition to carcinogenic and teratogenic potentials, $\mathrm{CP}$ has also well-known toxic effects on heart, bladder, and hematopoietic system and causes leucopenia and a reduction in platelet number (Langford, 1997).

Numerous studies have shown that CP exposure enhances intracellular reactive oxygen species (ROS) production, suggesting that biochemical and physiological disturbances may result from oxidative stress (Manda and Bhatia, 2003). Studies in mammals suggest that CP causes acute damage to the blood-forming tissues in the bone marrow, thereby causing transient reduction in circulating

Address for Correspondence: Adnan Ayhanci, Department of Biology, Faculty of arts and Science, F5 Building, Eskisehir Osmangazi University, Meselik Campus, Eskisehir 26480, Turkey; Fax: 90222 2393578. E-mail: aayhanci@ogu.edu.tr

(Received 27 February 2009; revised 26 April 2009; accepted 19 June 2009) 
PMNs (polymorphonuclear neutrophils), thus affecting the innate immune system. CP also causes a reduction in microsomal enzyme activity and reductions in the antioxidant defense system and also reduces specific immunity through direct depletion of lymphoid tissues, thus preventing the host from raising an adequate specific immune response (Kumari and Shaoo, 2005).

The combination of the drug together with a potent antioxidant may be the appropriate approach to reduce the side effects of CP (Selvakumar et al., 2006). Thus, in a study when CP was administrated with $\mathrm{ZnCl}_{2}$, there was a significant protection against CP-induced hematoxicity and urotoxicity observed in animals pretreated with $\mathrm{ZnCl}_{2}$ (Ayhanci et al., 2009). Antioxidants may ameliorate CP-induced myelosuppression. Selenium (Se) is a nutritionally essential trace element with anticarcinogenic properties. It is a constituent of several enzymes, such as glutathione peroxidase (GPx), phospholipidhydroperoxide, and thioredoxin reductase, which remove hydroperoxides formed during oxidative metabolism, thereby reducing the potential for oxidative damage to DNA, proteins, and polyunsaturated membrane phospholipids (Nomura et al., 2000; Spallholz, 2003). Se nutritionally acts by its enzymes, cytosolic GPx or membrane-bound phospholipidhydroperoxide, and thioredoxin reductase, to control levels of cellular hydroperoxides and the redox tone of cells that can damage proteins, cell and organelle membranes, and DNA (Spallholz, 2003). Se deficiency has been found to reduce GPx activity in rats, having a glomerular disease and in tubular epithelium of the normal rats (Jamba et al., 1997). Limited data from studies in humans suggest that Se supplementation may enhance immunity, including both humoral and cell-mediated responses (Hoffmann and Berry, 2008). It was demonstrated that Se is a highly effective modulator of the therapeutic efficacy and selectivity of anticancer drugs in nude mice bearing human tumor xenografts of colon carcinoma and squamous-cell carcinoma of the head and neck. Thus, the use of Se as a selective modulator of the therapeutic efficacy of anticancer drugs is new and novel (Cao et al., 2004). Human Se-deficiency diseases, such as Keshan disease (a human heart disease) and Kashin-Beck disease (a human rheumatoid condition), turned up in the 1980s in China and Russia. These and other diseases were all prevented by the addition of relatively small amounts of Se salts to the diet (Spallholz, 2003). Based on these facts, the possible protective effect of Se on CP-induced toxicity of the blood and bone marrow of rats were investigated in this study.

\section{Materials and Methods}

A total of 84 Sprague-Dawley rats of either sex, weighing 190-220 g, were used for the i.p. injection of CP (Endoxan; Sigma-Aldrich, Taufkirchen, Germany; C0768) and SLM (seleno-L-methionine; Sigma; S3132). Animals were given food and water ad libitium. The rats were randomly divided into the following experimental groups, each including 7 animals: Groups 1, 2, and 3 were treated with 50, 100 , or $150 \mathrm{mg} / \mathrm{kg}$ of $\mathrm{CP}$, respectively; groups 4 and 5 were treated with 0.4 and $0.8 \mathrm{mg} / \mathrm{kg}$ of SLM, respectively; groups 6,7 , or 8 were treated with respective CP plus $0.4 \mathrm{mg} / \mathrm{kg}$ of SLM; groups 9,10 , or 11 were treated with respective CP plus $0.8 \mathrm{mg} / \mathrm{kg}$ of SLM; and group 12 (control) were treated with saline.

The experimental procedure was followed as previously reported (Ayhanci et al., 2008). The animals in the first three groups received only CP in saline and were killed 3 days after the $\mathrm{CP}$ injection. The fourth and fifth groups received 0.4 or $0.8 \mathrm{mg} / \mathrm{kg}$ of SLM for 6 days. For the groups having CP plus SLM, SLM administration was started 3 days earlier than the CP administration and continued to the end of the experiment ( 6 days). On day 4 , the animals were weighed again, relative doses of CP were estimated, and CP plus SLM was administered together. On day 7 , blood samples were collected and bone marrow of animals were resected under anesthesia. The control group was injected with the same amount of saline and killed at day 7 with all the other mentioned groups.

Under the ether anesthesia, the blood samples were collected by cardiac puncture, and then the animals were killed at either days 4 or 7 . Both femurs were dissected, and bone marrow was flushed with saline into a test tube. Homogenized bone marrownucleated cells and blood cells were counted with a cell counter (Coulter).

The results were expressed as means \pm standard error of the mean. Statistical analysis was performed by using one-way analysis of variance (ANOVA), followed by Tukey's multiple range test, and $P<0.05$ was accepted as a statistical significance. Triplicate samples from each animal were taken, and the results were expressed as a mean for each animal.

\section{Results}

The increase in the leukocyte and platelet numbers for the group that received $0.4 \mathrm{mg} / \mathrm{kg}$ of SLM were not statistically significant $(P>0.05)$, whereas the increase in bone marrow-nucleated cell number was statistically significant $(P<0.01)$. In the $0.8-\mathrm{mg} / \mathrm{kg}$ 
SLM group the increase in leukocyte number, compared to the control group, was not statistically significant $(P>0.05)$, but the increase in the number of the thrombocyte $(10 \%)$ and bone marrow-nucleated cells (25\%) was highly significant $(P<0.001$; Figure 1$)$.

When used alone, doses of 50,100 , or $150 \mathrm{mg} / \mathrm{kg}$ of CP caused 78,89 , and $92 \%$ reduction in the number of leukocytes, respectively $(P<0.001)$. Administered together with respective doses of $\mathrm{CP}, 0.4 \mathrm{mg} / \mathrm{kg}$ of SLM reduced the number of leukocytes by 34,55 , and $89 \%$, respectively $(P<0.01)$. A $57 \%$ significant recovery was obtained only in the $50+0.4 \mathrm{mg} / \mathrm{kg}$ group. Administered together with respective doses of CP, $0.8 \mathrm{mg} / \mathrm{kg}$ of SLM reduced the number of leukocytes by 74,87 , and $91 \%$, respectively $(P<0.001)$,

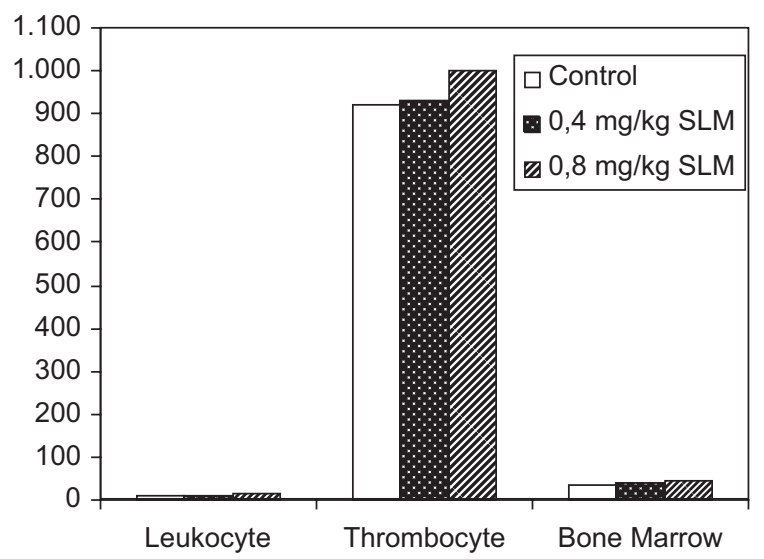

Figure 1. The number of peripheral leukocytes, thrombocytes, and bone marrow- nucleated cells with the presence of saline, $0.4 \mathrm{mg} / \mathrm{kg}$ of SLM, and $0.8 \mathrm{mg} / \mathrm{kg}$ of SLM.

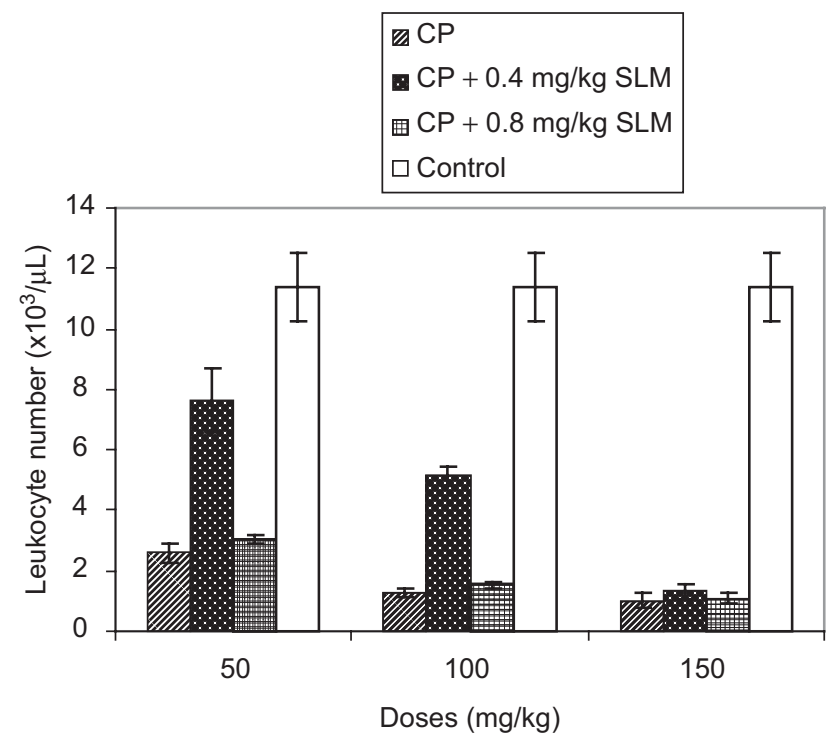

Figure 2. The number of peripheral leukocytes with the presence of saline, respective doses of CP, or CP plus SLM. whereas $0.8 \mathrm{mg} / \mathrm{kg}$ of SLM did not have a protective effect on CP toxicity of the leukocytes at these doses (Figure 2).

The number of platelets in rats treated only with 50,100 , or $150 \mathrm{mg} / \mathrm{kg}$ of CP alone decreased by 22 , 33 , or $52 \%$, respectively $(P<0.001)$. Administered together with respective doses of $\mathrm{CP}, 0.4 \mathrm{mg} / \mathrm{kg}$ of SLM reduced the number of thrombocytes by 5,22 , and $49 \%$, respectively $(P<0.05)$. An $83 \%$ significant recovery was obtained only in the $50+0.4 \mathrm{mg} / \mathrm{kg}$ $\mathrm{CP}+\mathrm{SLM}$ group. Compared to the $100-\mathrm{mg} / \mathrm{kg}$ $\mathrm{CP}$ group, the increase in platelet number of the $100+0.4 \mathrm{mg} / \mathrm{kg} \mathrm{CP}+\mathrm{SLM}$ group was $33 \%$, whereas the increase was $6 \%$ in the $150+0.4 \mathrm{mg} / \mathrm{kg} \mathrm{CP}+\mathrm{SLM}$ group. Administered together with respective doses of $\mathrm{CP}, 0.8 \mathrm{mg} / \mathrm{kg}$ of SLM reduced the number of thrombocytes by 22,25 , and $25 \%$, respectively $(P<0.001)$, whereas $0.8 \mathrm{mg} / \mathrm{kg}$ of SLM was not effective in the prevention of thrombocytopenia caused by $50 \mathrm{mg} / \mathrm{kg}$ of $\mathrm{CP}$, but it was highly effective in preventing that caused by 100 and $150 \mathrm{mg} / \mathrm{kg}$ of CP (25 and $52 \%$, respectively; Figure 3).

The number of bone marrow-nucleated cells decreased by 72,90 , or $94 \%$ after the administration of 50,100 , or $150 \mathrm{mg} / \mathrm{kg}$ of $\mathrm{CP}(P<0.001)$. When compared with the respective three doses of $\mathrm{CP}$, $0.4 \mathrm{mg} / \mathrm{kg}$ of SLM caused about 52,50 , or $42 \%$ recovery in the number of bone marrow-nucleated cells, respectively $(P<0.05)$. Administered together with respective doses of CP, $0.8 \mathrm{mg} / \mathrm{kg}$ of SLM reduced the number of bone marrow-nucleated cells by 56,87 , and $92 \%$, respectively $(P<0.001$; Figure 4$)$.

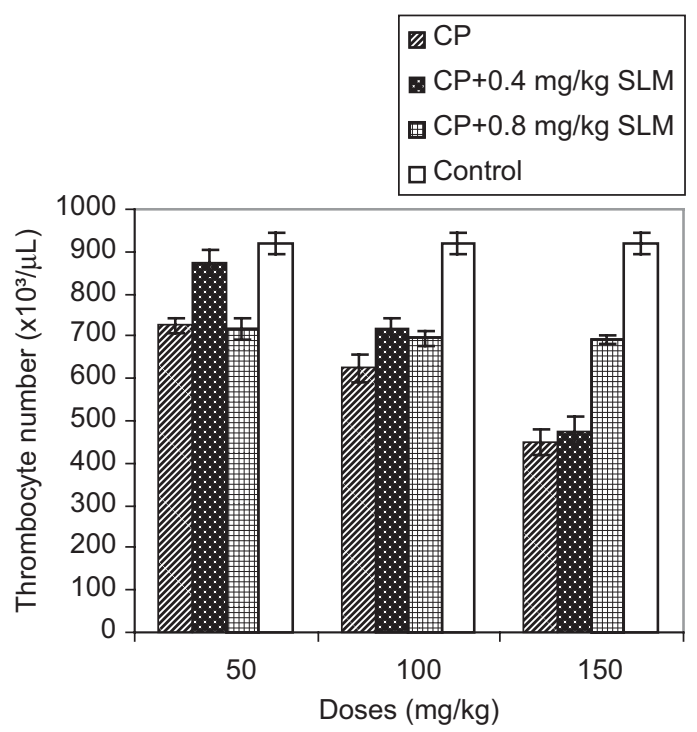

Figure 3. Blood thrombocyte number of the rats after treatment with saline, respective doses of CP, or CP plus SLM. 


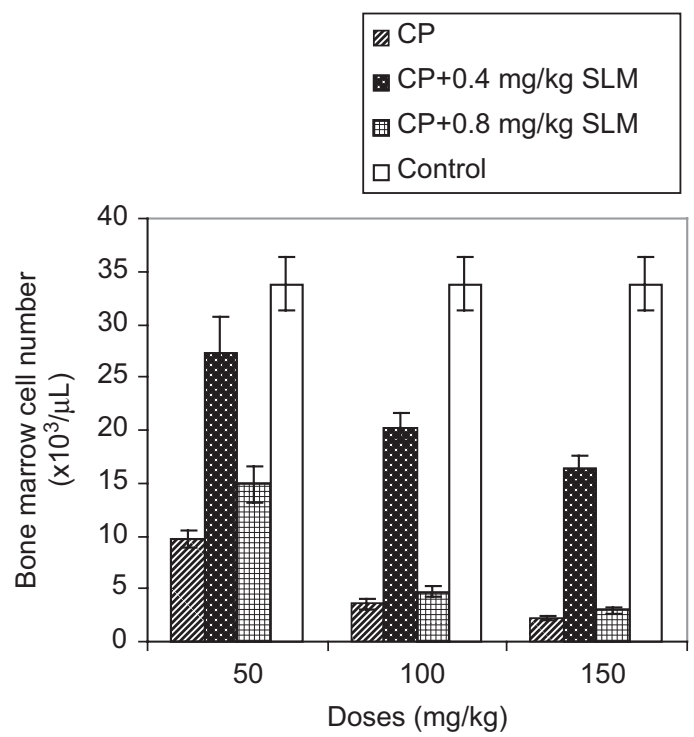

Figure 4. The number of bone marrow-nucleated cells in the control, CP-, or CP plus SLM-treated groups.

\section{Discussion}

The chemotherapeutic usefulness of alkylating agents are derived from their ability to form a variety of DNA adducts that sufficiently alter DNA structure or function or both so as to have a cytotoxic effect on the cells. Many of them undergo a very complex activation process before they can generate reactive intermediates. Initial activation reaction of $\mathrm{CP}$ carried out by the microsomal oxidation system in the liver produces 4-hydroxy CP, a cytotoxic metabolite, which diffuses from hepatocytes into plasma and is distributed throughout the body. Then, 4-hydroxy CP is further converted to other cytotoxic metabolites, such as acrolein and phosphoramide mustard (PAM). PAM is known to cause myelosuppression (Kumar and Kuttan, 2005; Liang et al., 2007). Myelosuppression is a major potential toxic and dose-limiting side effect of CP. CP causes cross-linking of DNA and inhibition of DNA synthesis by acting on both cyclic and intermitotic cells, resulting in general depletion of immune component cells (George et al., 2008). In this study, CP showed up to $92 \%$ toxicity on the circulating white blood cells (WBCs) of rats in a dose-dependent manner. Similarly, after the single dose of CP injection, leukocyte counts began to fall (Fraiser et al., 1991; Langford, 1997; Bergsagel et al., 1968). Further, administration of a single dose of $40 \mathrm{mg} / \mathrm{kg} \mathrm{CP}$ to baboons resulted in transient reduction in WBC count (Schuurman et al., 2005). In our study, when $0.4 \mathrm{mg} / \mathrm{kg}$ of SLM was used together with $50 \mathrm{mg} / \mathrm{kg}$ of CP, a total recovery of leukocytes was about $44 \%$; however, when $0.8 \mathrm{mg} / \mathrm{kg}$ of SLM was administrated with the same dose of CP, a total recovery of leukocytes was about $4 \%$. These results indicate that $0.8 \mathrm{mg} / \mathrm{kg}$ of SLM does not exhibit a high protection when used with CP. Compared to the control group, the increase in leukocyte and platelet numbers in the $0.4-\mathrm{mg} / \mathrm{kg}$ SLM group was not significant $(P>0.05)$, whereas the increase in the bone marrow-nucleated cell number was found to be significant $(P<0.01)$. Compared to the control group, the increase in leukocyte number was not found to be statistically significant in the $0.8-\mathrm{mg} /$ $\mathrm{kg}$ SLM group, whereas the increase in platelet (10\%) and bone marrow-nucleated cell (25\%) number was found to be highly significant. Neither 0.4 nor $0.8 \mathrm{mg} / \mathrm{kg}$ of SLM protected the leukocytes from the toxic effect of $150 \mathrm{mg} / \mathrm{kg}$ of CP. The toxic effect of our doses of CP on the bone marrow-nucleated cell was similar to the effects on leukocytes, but $0.4 \mathrm{mg} / \mathrm{kg}$ of SLM appeared to be more effective on bone marrow. The best recovery, of about $52 \%$, was obtained with $0.4 \mathrm{mg} / \mathrm{kg}$ of SLM used together with $50 \mathrm{mg} / \mathrm{kg}$ of CP; but even with the highest ( $150 \mathrm{mg}$ ) CP dose, there was about $42 \%$ recovery of the bone marrow cells. Olas and Wachowicz (1997) reported that the administration of sodium selenite appears to reduce cisplatin toxicity without inhibiting the antitumor activity of cisplatin. Recently, Weijl et al. (2004) have found that supplementation with a higher dose of Se in combination with other antioxidants (e.g., vitamins $\mathrm{C}$ and E) could correlate with cisplatin-induced ototoxicity and nephrotoxicity. Moreover, Se administration for 3 months resulted in a significant increase of WBC (Sieja and Talerczyk, 2004). The deprivation of Se can reduce the protection against oxidative stress and impair immunocompetence, as certain cancer cells appear to have acquired a selective survival advantage that is apparent under conditions of Se deficiency and oxidative stress (Zeng and Combs, 2008).

The least toxic effect of $\mathrm{CP}$ was observed on the circulating thrombocytes, with $150 \mathrm{mg} / \mathrm{kg} \mathrm{CP}$ causing only about $52 \%$ reduction in blood platelet count. A similar result was reported, indicating that reduction in platelets occurs only at high doses of CP (Bergsagel et al., 1968). There was a complete protection when we used $0.4 \mathrm{mg} / \mathrm{kg}$ of SLM with $50 \mathrm{mg} / \mathrm{kg}$ of CP. The number of platelets in rats treated with 50,100 , or $150 \mathrm{mg} / \mathrm{kg}$ of CP decreased by 22,33 , and $52 \%$, respectively. Administered together with respective doses of $\mathrm{CP}, 0.4 \mathrm{mg} / \mathrm{kg}$ of SLM reduced the number of thrombocytes by 5,22 , and $49 \%$, respectively. About a $83 \%$ significant recovery was obtained only in the $50+0.4 \mathrm{mg} /$ $\mathrm{kg} \mathrm{CP+SLM} \mathrm{group.} \mathrm{Compared} \mathrm{to} \mathrm{the} 100-\mathrm{mg} / \mathrm{kg} \mathrm{CP}$ group, the platelet number in the $100+0.4 \mathrm{mg} / \mathrm{kg}$ $\mathrm{CP}+\mathrm{SLM}$ group increased by $33 \%$, whereas the increase in platelet number in the $150+0.4 \mathrm{mg} / \mathrm{kg} \mathrm{CP}+\mathrm{SLM}$ group was estimated as $6 \%$. Administered together with respective doses of $\mathrm{CP}$, compared to the control, 
$0.8 \mathrm{mg} / \mathrm{kg}$ of SLM reduced the number of thrombocytes by 22,25 , and $25 \%$, respectively, whereas $0.8 \mathrm{mg} /$ $\mathrm{kg}$ of SLM was not found to be effective in the prevention of thrombocytopenia caused by $50 \mathrm{mg} / \mathrm{kg}$ of CP, but it was found to be highly effective in the prevention of thrombocytopenia caused by 100 and $150 \mathrm{mg} /$ $\mathrm{kg}$ of CP (25 and 52\%, respectivly). Further studies are needed to substantiate the effect of Se on CP toxicity of the platelets.

\section{Conclusions}

In conclusion, Se alone is not toxic to bone marrow or blood cells, but CP is toxic to bone marrow, leukocytes, and platelets. However, depending on the dose, Se protects the animals from the toxic effect of $\mathrm{CP}$. The best recovery was obtained when $0.4 \mathrm{mg} / \mathrm{kg}$ of SLM was given in combination with $50 \mathrm{mg} / \mathrm{kg}$ of CP. Our findings suggest that at the appropriate concentration, Se could be a potentially effective drug in the treatment of CP-induced damage and could be used in the prevention and treatment of CP toxicity. Additional experimentation should be performed to explore the underlying mechanism of selenium protection against $\mathrm{CP}$ toxicity.

\section{Acknowledgments}

Declaration of interest: The authors declare that there are no conflicts of interest.

\section{References}

Ayhanci, A., Uyar, R., Aral, E., Kabader, S., Appak, S. (2008). Protective effect of zinc on cyclophosphamide-induced hematoxicity and urotoxicity. Biol Trace Elem Res 126:186-193.

Anderson, D., Bishop, J. B., Garner, R. C., Ostrosky-Wegman, P., Selby, P. B. (1995). Cyclophosphamide: review of its mutagenicity for an assessment of potential germ cell risk. Mutat Res 330:115-181.

Bergsagel, D. E., Roberson, G. L., Hasselback, R. (1968). Effect of cyclophosphamide on advanced lung cancer and haematological toxicity of large, intermittent intravenous doses. Can Med Assoc J 98:532-538.

Cao, S., Durrani, F. A., Rustum, Y. M. (2004). Selective modulation of the therapeutic efficacy of anticancer drugs by selenium containing compounds against human tumor xenografts. Clin Cancer Res 10:2561-2569.
Fraiser, L. H., Kanekal, S., Kehrer, J. P. (1991). Cyclophosphamide toxicity: characterizing and avoiding the problem. Drugs 42:781-795.

George, K. S., Rajesh, R., Sunil Kumar, S., Sulekha, B., Balaram, P., (2008). A polyherbal ayurvedic drug-Indukantha Ghritham as an adjuvant to cancer chemotherapy via immunomodulation. Immunobiology 213:641-649.

Hoffmann, P. R., Berry, M. J. (2008). The influence of selenium on immune responses. Mol Nutr Res 52:1273-1280.

Jamba, L., Nehru, B., Bansal, M. P. (1997). Selenium supplementation during cadmium exposure: changes in antioxidant enzymes and the ultrastructure of the kidney. J Trace Elements Exp Med 10:233-242.

Kumar, K. B. H., Kuttan, R (2005). Chemoprotective activity of an extract of Phyllanthus amarus against cyclophosphamideinduced toxicity in mice Phytomedicine 12:494-500.

Kumari, J., Shaoo, P. K. (2005). Effects of cyclophosphamide on the immune system and disease resistance of Asian catfish Clarias batrachus. Fish Shellfish Immunol 19: 307-316.

Langford, C. A. (1997). Complications of cyclophosphamide therapy. Eur Arch Otorhinolaringol 254:65-72.

Liang, J., Huang, M., Duan, W., Yu, X-Q., Zhou, S. (2007). Design of new oxazaphosphorine anticancer drugs. Curr Pharm Des 13:963-978.

Manda, K., Bhatia, A. L. (2003). Prophylactic action of melatonin against cyclophosphamide-induced oxidative stress in mice. Cell Biol Toxicol 19:367-372.

Nomura, A. M. Y., Lee, J., Stemmermann, G. N., Combs, G. F. (2000). Serum selenium and subsequent risk of prostate cancer. Cancer Epidemiol Biomark Prev 9:883-887.

Olas, B., Wachowicz, B. (1997). Selenium in the cytotoxicity of cisplatin. Postepy Hyg Med Dos 51:95-108.

Schuurman, H. J., Smith, H. T., Cozzi, E. (2005). Tolerability of cyclophosphamide and methotrexate induction immunosuppression in nonhuman primates. Toxicology 213:1-12.

Selvakumar, E., Prahalathan, C., Sudharsan, P. T., Varalakshmi, P. (2006). Chemoprotective effect of lipoic acid against cyclophosphamide-induced changes in the rat sperm. Toxicology 217:71-78.

Shah,A.S., Wakade,A.S., Juvekar,A.R.(2008).Immunomodulatory activity of methanolic extract of Murraya koenigii (L) Spreng leaves. Ind J Exp Biol 46 (7): 505-509.

Sieja, K., Talerczyk, M. (2004). Selenium as an element in the treatment of ovarian cancer in women receiving chemotherapy. Gynecol Oncol 93:320-327.

Spallholz, J. E. (2003). Use of selenium to prevent and treat cancer in the new millennium. J Kor Assoc Cancer Prev 8:9-23.

Weijl, N. I., Elsendoorn, T. J., Lentjes, E. G., Hopman, G. D., Wipkink-Bakker, A., Zwinderman, A. H., et al. (2004). Supplementation with antioxidant micronutrients and chemotherapy-induced toxicity in cancer patients treated with cisplatin-based chemotherapy: a randomised, double-blind, placebo-controlled study. Eur J Cancer 40:1713-1723.

Zeng, H., Combs, J. G. F. (2008). Selenium as an anticancer nutrient: roles in cell proliferation and tumor cell invasion. J Nutr Biochem 19:1-7. 